\title{
Acoustic Measurements for Determination of the Materials Damping Using A Sound Source Localisation System
}

\author{
J. Göken ${ }^{1)}$, J. Swiostek ${ }^{2)}$, H. Hurdelbrink ${ }^{1)}$ and U. Keil ${ }^{1)}$
}

1) Faculty of Maritime Studies, University of Applied Sciences Emden/Leer, Bergmannstr. 36, 26789 Leer, Germany

2) Stalomax ${ }^{\mathrm{TM}}$, Company of High-Precision Mechanics, ul. Parkingowa 45, 37450 Stalowa Wola, Poland

[Manuscript received 7 September 2012, in revised form 9 November 2012]

(C) The Chinese Society for Metals and Springer-Verlag Berlin Heidelberg

\begin{abstract}
Noise measurements are especially a problem when the object under investigation is largely dimensioned and can only be measured from the distance. To obtain information about the location of noise generation, a measurement technique which makes sound visible in order to introduce further specific technical measures is advantageous.

The question is if the time dependence of the signal got from such a non touching and non destructive acoustic method has the potential to calculate the materials damping from. Using a small sound source localization system (Microflown ${ }^{\mathrm{TM}}$ probe), specimens of magnesium alloys with different grain sizes obtained by hydrostatic extrusion were investigated. It has been demonstrated that the fine grained microstructure led to a lower damping and its dependence on the strain was reduced.

In this context, acoustic measurements by a sound source localisation system which makes materials characterization possible could be used as a quality tool to detect changes in highly stressed components. This approach allows to promote a selective substitution of conventional materials by more innovative ones. The offshore sector is considered to be a field of application: Wind turbines produce noise emission which stems mainly from turbulences at the tips of the rotor blades and vibrations of components inside the nacelle $(e . g$. gearbox, generator, $\cdots$ ). If the vibration amplitudes are too high, microcracks of components can lead to failure over the long term. The monitoring of microstructural changes using a larger type of a sound source localisation system is considered as an innovative technical approach with respect to maintenance activities.
\end{abstract}

KEY WORDS: Magnesium; Noise measurements; Microflown ${ }^{\mathrm{TM}}$; Damping

\section{Introduction}

The comfort of e.g. cars, trains and airplanes will considerably enhance when the emitted structureborne noise can be prevented. Conventional microphones measure the sound pressure caused by the change of the sound wave. However, a Microflown ${ }^{\mathrm{TM}}$ velocity microphone (Microflown ${ }^{\mathrm{TM}}$ probe) determines the particle motion of the air directly: Two tiny platinum wires are heated up to $200{ }^{\circ} \mathrm{C}$. The sound wave in the air lets the air molecules flow past at

\footnotetext{
† Corresponding author. Prof., Ph.D.; Tel: +49 491928175021 Fax:+49 49192817 5011; E-mail address: juergen.goeken@hsemden-leer.de (J. Göken)
}

DOI: $10.1007 / \mathrm{s} 40195-012-0155-8$ different rates to these wires. This differential cooling changes the electrical resistance of the wires representing the signal of the sound velocity. The generated voltage difference is proportional to the particle velocity. The Microflown ${ }^{\mathrm{TM}}$ probe as used for the measurements consists of a pressure microphone and a particle velocity microphone ${ }^{[1]}$. In order to reveal the characteristics of the regular probe in Table 1 the acoustical properties of the Microflown ${ }^{\mathrm{TM}}$ element compared to a commercially available microphone are shown.

The sound emission of different magnesium alloys was recorded using the Microflown ${ }^{\mathrm{TM}}$ probe in particle velocity modus. It is well known that magnesium and magnesium alloys serve as green metallic material for the $21^{\text {st }}$ century because of their low density and 
Table 1 Acoustical properties of the Microflown ${ }^{\mathrm{TM}}$ probe

\begin{tabular}{|c|c|c|c|c|}
\hline & Frequency range & Upper sound level & Polar pattern & Directivity \\
\hline Microphone element & $20 \mathrm{~Hz}-20 \mathrm{kHz}$ & $110 \mathrm{~dB}$ & Omnidirectional & Omnidirectional \\
\hline Microflown $^{\mathrm{TM}}$ element & $0.1 \mathrm{~Hz}-20 \mathrm{kHz}$ & $125 \mathrm{~dB}$ & Figure of eight & Directive \\
\hline
\end{tabular}

energy-saving capacity ${ }^{[2]}$. However, the application of magnesium alloys is restricted to a limited range because of their poor workability at room temperature (RT) which is attributed to their hcp crystal structure. Grain refinement by thermomechanical processing is considered to give magnesium alloys better strength and ductility ${ }^{[3]}$. Hydrostatic extrusion is a well suited technique for producing fine-grained microstructures. Magnesium alloys combine both high damping potential and lightness by their low specific density ${ }^{[4]}$. However, yield strength and damping of these alloys generally behave contrarily to each other ${ }^{[5,6]}$ because both properties are mainly controlled by dislocation motion. Whereas the strength can be increased by restricted dislocation motion, the damping in this case is lowered. This has to be confirmed on the basis of a new method of contact-free measurement using the mentioned Microflown ${ }^{\mathrm{TM}}$ velocity microphone.

Basis for the use of the Microflown ${ }^{\mathrm{TM}}$ probe is that the displacement as a function of time $(t)$ can be expressed as

$$
A(t)=A_{0} \sin (\omega t)
$$

where $\omega$ is the angular velocity and $A_{0}$ the start amplitude.

The sound velocity $v$ is determinable from the derivative of Eq. (1) with respect to time

$$
\frac{\mathrm{d}(A(t))}{\mathrm{d} t}=v(t)=A_{0} \omega \cos (\omega t)
$$

It implies that a decrease of the sound pressure corresponds to a decrease of the particle velocity. The decay of the amplitudes $A_{n}$ of $A(t)$ characterizing the damping of the materials vibration is the same as for the particle velocity. Thus, the signal from the Microflown ${ }^{\mathrm{TM}}$ probe can be taken for investigating the materials damping.

\section{Experimental}

\subsection{Clamping of the specimen}

All samples were clamped at one side (bending beam) to a special fixing construction. The purpose of this construction was to keep the sample tight, eliminating unwanted sound absorptions from other parasitic vibrations. For this reason the construction itself had to be mounted to a heavy steel block fixed to the ground. As seen in Fig. 1, the sample was installed between two steel plates. Two semicircles with the same diameter like the width of the samples were drilled into each one of the plates to have an

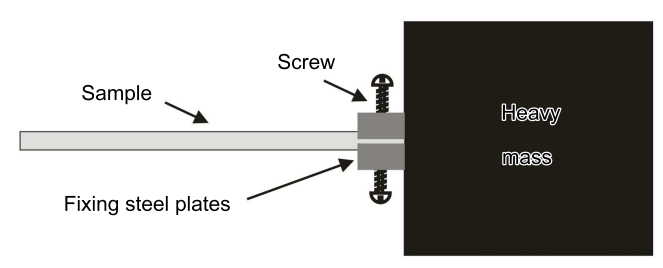

Fig. 1 Fixing construction of the sample

optimized contact pressure. This ensures an increase in static friction and thus an avoidance of unwanted external energy losses (no surface motion between the clamped part of the sample and the plates) of the decaying oscillation.

\subsection{Materials damping}

All damping measurements were carried out at room temperature in a room with reduced sound level. The Microflown ${ }^{\mathrm{TM}}$ probe was fixed to a flexible holder which made it easy to align it to any position. On the one hand the motion of air particles (particle velocity) is necessary to get a measuring signal, but on the other hand the motion is not only dependent on the vibration of the sample but also on parasitic effects like air vortexes. These impacts were reduced by positioning the Microflown ${ }^{\mathrm{TM}}$ probe near the clamped side of the sample with a distance of about $3 \mathrm{~mm}$ from it. Sample and probe were perpendicular to one another. The sample was manually excited to its resonance frequency (about $70 \mathrm{~Hz}$ ) and the particle velocity caused during the free decay of the bending beam measured by the Microflown ${ }^{\mathrm{TM}}$ probe. A two-channel signal conditioner converted the data which were recorded by a computer afterwards. In Fig. 2 the measured particle velocity is plotted versus the time. From this curve the decay curve (grey points) can be received by determination of the maxima of the decreasing signal. The finding of the maxima (peak values) was done by a self-written program. This procedure is not trivial because the recorded signal was noisy and the peaks had to be determined as an average value from the data at the expected maximum.

The peak values of the decaying oscillation are necessary to calculate the materials damping in terms of the logarithmic decrement $\delta$. Damping is the energy dissipation of a material or system under cyclic stress. There are many methods for measuring the materials damping. Logarithmic decrement method is used to measure damping in time domain: The reduction of the vibration amplitude as a function of the time is recorded (Fig. 3) whereas the damping constant $\beta$ 


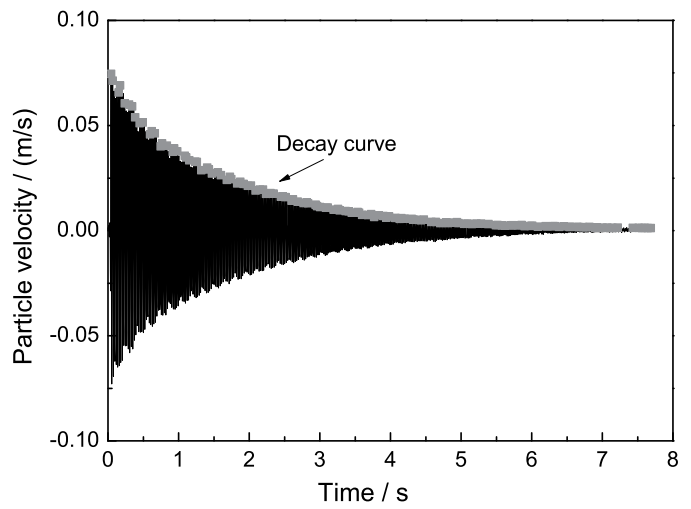

Fig. 2 Determination of the decay curve from the timedependent particle velocity data

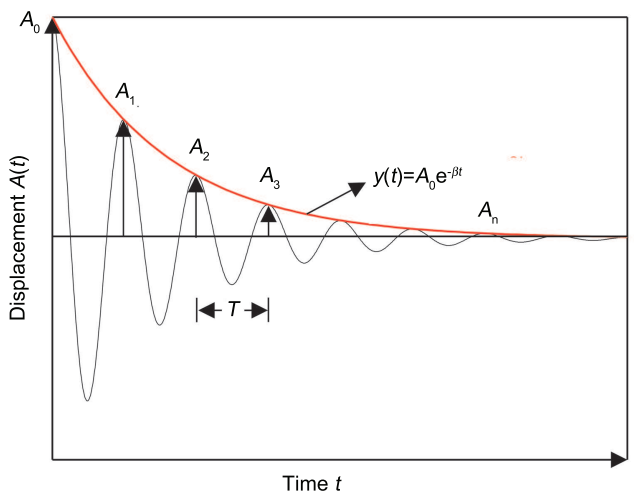

Fig. 3 Damped vibration: $A(t)$ is the time dependent displacement function; $y(t)$ is the time dependent decay function

can be determined from the decay of the envelope. Taking into consideration the cycle time $T$ the logarithmic decrement $\delta$ is got as the product $\beta T$ or as the natural logarithmic value of the ratio of two adjacent peak values $\left(A_{n}, A_{n+1}\right)$ in free decay vibration, Eq. (3).

$$
\delta=\beta T=\ln \left(\frac{A_{n}}{A_{n+1}}\right)
$$

If one considers the drop in amplitude in $k$ successive cycles then the logarithmic decrement is given by

$$
\delta=\frac{1}{k} \ln \left(\frac{A_{n}}{A_{n+k}}\right)
$$

\subsection{Strain dependent damping}

In Fig. 3 the logarithmic decrement $\delta$ is assumed to be constant but its dependence on the amplitude of materials vibration can lead to a strong change of this value. In that case, the use of Eq. (3) is disadvantageous because only an "average" value of logarithmic decrement $\delta$ can be received (constant damping behavior over the total strain interval). Thus, Eq. (4) is experimentally more reliable because $\delta$ is dependent on the materials strain which usually changes during the decay. Commonly, the damping $\delta$ is plotted as a function of the maximum strain $\varepsilon_{\max }$ occurring near the clamped side of the specimen. $\varepsilon_{\max }$ can be calculated from the length $l$ of the specimen, its thickness $a$ and the elongation $z^{\prime}$ (amplitude of vibration), Fig. 4 . It applies the following Eq. (5):

$$
\varepsilon_{\max }=\frac{3 a}{2 l^{2}} z^{\prime}
$$

The recorded maximum value of the decreasing amplitudes of the particle velocity can directly be attributed to the elongation $z^{\prime}$, Fig. 5. Due to the proportionality the derivation of the curve is constant and receivable from Eq. (6),

$$
c=\frac{\Delta z^{\prime}}{\Delta A_{0}}
$$
(5))

By using Eq. (6) the maximum strain $\varepsilon_{\max }$ (Eq. is expressible as

$$
\varepsilon_{\max }=\frac{3 a}{2 l^{2}} c A
$$

where $A$ is the current amplitude taken from the decay curve shown in Fig. 3.

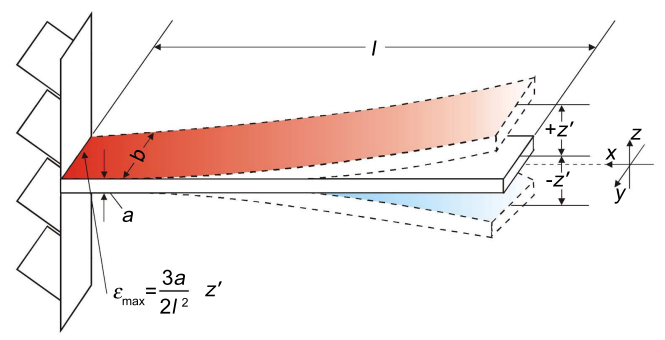

Fig. 4 Maximum strain $\varepsilon_{\text {max }}$ near the clamped side of the bending beam with length $l$, width $b$ and thickness $a$

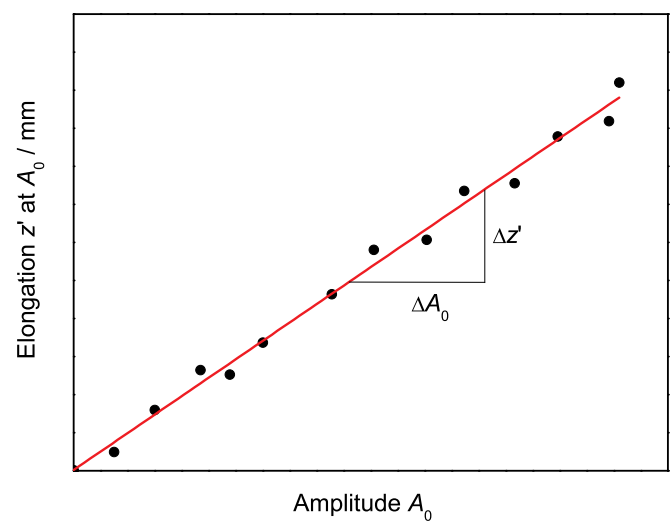

Fig. 5 Correlation between the maximum value of the decreasing amplitude $A_{0}$ and the elongation $z^{\prime}$ at $A_{0}$ 


\subsection{Background damping}

First damping measurements were performed using the reference sample of NiCr19NbMo $(\rightarrow$ a highstrength, corrosion-resistant nickel chromium material). Because of its low damping capacity other effects (e.g. damping by external friction due to clamping) become more dominant and can be identified as background damping (offset). This background damping is allowed to be subtracted from the measured damping of the used specimens since damping may be superimposed one on the other (Fig. 6).

Fig. 7 shows the measured offset damping. The mean value $\bar{\delta}_{\text {of }}$ representing $\delta_{\text {of }}$ over a strain range from $2.4 \times 10^{-5}$ to nearly $5 \times 10^{-5}$ can be calculated as $\bar{\delta}_{\text {of }} \approx 1.6 \times 10^{-3}$. In this region the strain independent part of the materials damping is expected. It is obvious that the relative error of $\bar{\delta}_{\text {of }}$ of about $62 \%$ is high and should be reduced. The situation is further aggravated by the fact that increased turbulence can occur at the edge of the samples which influences the offset damping. This problem has to be considered during the measurements and is experimentally not easy to solve. Only in case of a high materials damping the offset damping is negligible.

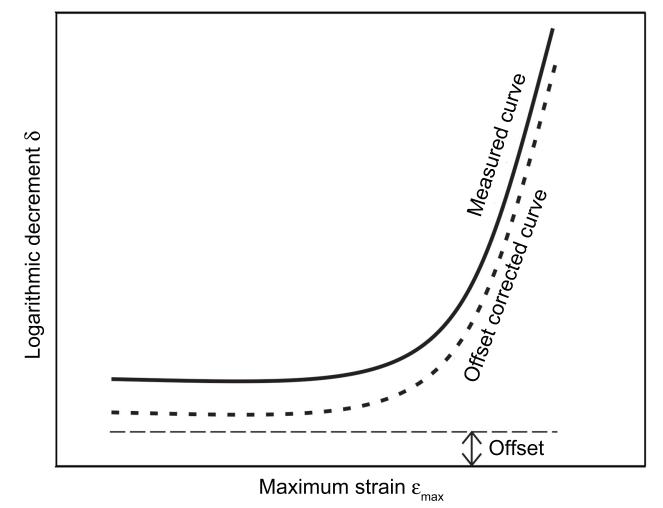

Fig. 6 Subtraction of background damping labeled as offset damping

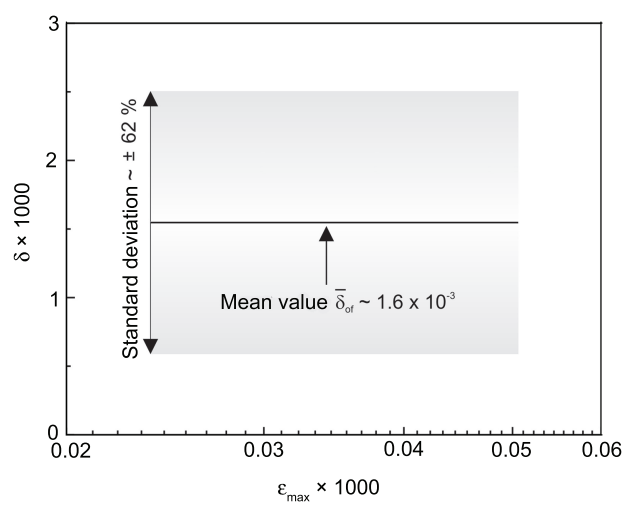

Fig. 7 Experimentally determined offset damping

\subsection{Used materials and their production}

According to Fig. 8 where the damping of different materials in terms of the inverse quality factor $Q^{-1}$ (with $Q^{-1}=\delta / \pi$ ) is plotted versus the Young's modulus of elasticity $E$, magnesium alloys show a broad damping capacity. This broadness can be explained by the variety of magnesium alloys but does not take into account the individual production process which would probably expand the corresponding area of magnesium alloys in Fig. 8. The hydrostatic extrusion process which is shown in the following section leads to a fine-grained microstructure and, thus, to a significant change of the damping. This result was received from own damping measurements ${ }^{[6]}$. Due to this process the logarithmic decrement reduces at higher strains compared to magnesium alloys produced by casting and becomes nearly independent from the strain up to $\varepsilon_{\max }=1 \times 10^{-3[6]}$.

DC-cast billets in as-cast condition from the magnesium alloys AZ31 and AZ61 were machined and solution treated afterwards to gain a homogenous microstructure. Their individual chemical composition is shown in Table 2 .

The hydrostatic extrusion process (Fig. 9) is a form giving technology and can be used for the production of magnesium profiles.

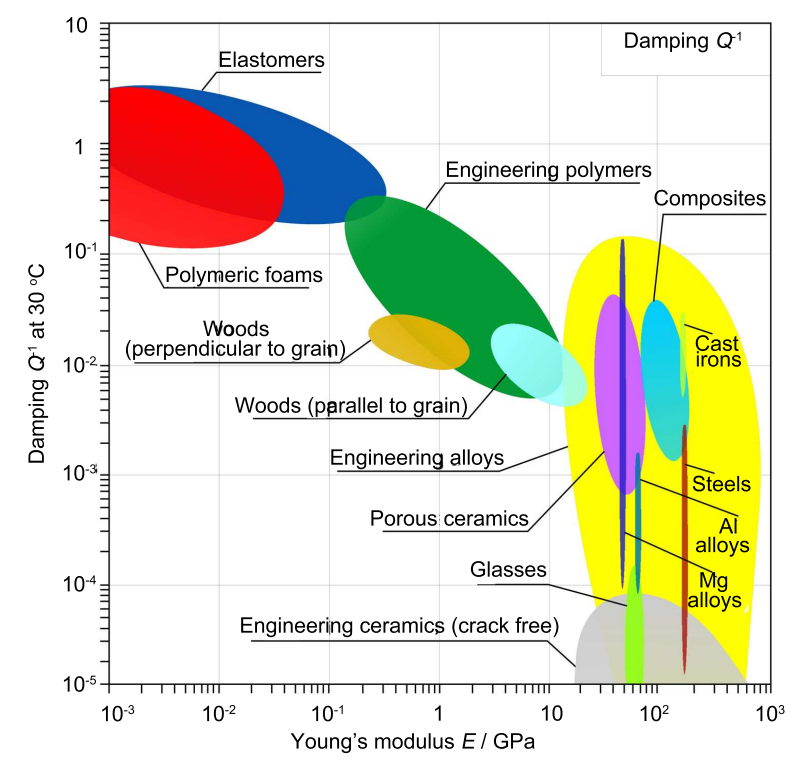

Fig. 8 Damping of different materials, following the synopsis of Ashby ${ }^{[7]}$

Table 2 Chemical composition (wt.\%) of AZ31 and AZ61

\begin{tabular}{ccccc}
\hline Alloy & Al & Zn & Mn & Mg \\
\hline AZ31 & 2.9 & 0.98 & 0.29 & Bal. \\
AZ61 & 6.5 & 0.99 & 0.2 & Bal. \\
\hline
\end{tabular}


A billet is pressed through the die by using hydrostatic medium (castor oil) which leads to a hydrostatic pressure. Friction can be ignored due to the use of the hydrostatic medium. This extrusion method allows processing at low temperature and higher extrusion rates of complex materials. Due to different heating a different recrystalization dynamics occurs which leads to a finer grain size after hydrostatic extrusion, Fig. 10. A detailed description of hydrostatic extrusion can be found elsewhere ${ }^{[9]}$.

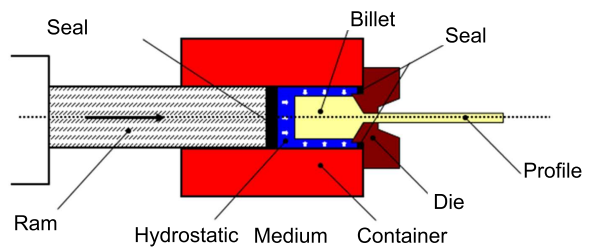

Fig. 9 Principle of the hydrostatic extrusion process ${ }^{[8]}$
It is well known that alloy and process parameters influence the mechanical properties of extruded magnesium components because solid solution hardening and grain refinement can significantly be controlled. Both are hardening mechanisms determining the strength and damping behaviour of a metal. The used extrusion parameters are given in Table 3 whereas the resulting materials characteristics can be taken from Table 4.

For comparison, the cast magnesium alloy AZ61 and another commercially available cast magnesium alloy AZ91 were investigated whose individual microstructure is shown in Fig. 11. Table 5 gives details on the chemical composition of AZ91.

It has to be pointed out that the average grain size of the AZ61 alloy in cast condition was about $(659.3 \pm 210.3) \mu \mathrm{m}$ and of AZ91 (1418.7 \pm 127.3$) \mu \mathrm{m}$ being nearly 100 and 300 times higher, respectively,

Table 3 Extrusion parameters

\begin{tabular}{|c|c|c|c|c|c|}
\hline Alloy & \multicolumn{2}{|c|}{ Extrusion temperature $/{ }^{\circ} \mathrm{C}$} & Extrusion ratio & \multicolumn{2}{|c|}{ Extrusion rate $/(\mathrm{m} / \mathrm{min})$} \\
\hline AZ31 & \multicolumn{2}{|c|}{300} & $1: 28$ & \multicolumn{2}{|c|}{8} \\
\hline AZ61 & \multicolumn{2}{|r|}{300} & $1: 28$ & \multicolumn{2}{|r|}{8} \\
\hline Alloy & Condition & $\begin{array}{c}\text { Average grain } \\
\text { size } / \mu \mathrm{m}\end{array}$ & $\begin{array}{c}\text { Yield } \\
\text { strength } / \mathrm{MPa}\end{array}$ & $\begin{array}{l}\text { Ultimate tensile } \\
\text { strength } / \mathrm{MPa}\end{array}$ & Hardness / HV10 \\
\hline AZ31 & $\begin{array}{c}\text { Hydrostatically } \\
\text { extruded }\end{array}$ & $4 \pm 1$ & 255 & 313 & $87.6 \pm 14.3$ \\
\hline AZ61 & $\begin{array}{c}\text { Hydrostatically } \\
\text { extruded }\end{array}$ & $5 \pm 1$ & 229 & 331 & $92.9 \pm 4.0$ \\
\hline
\end{tabular}

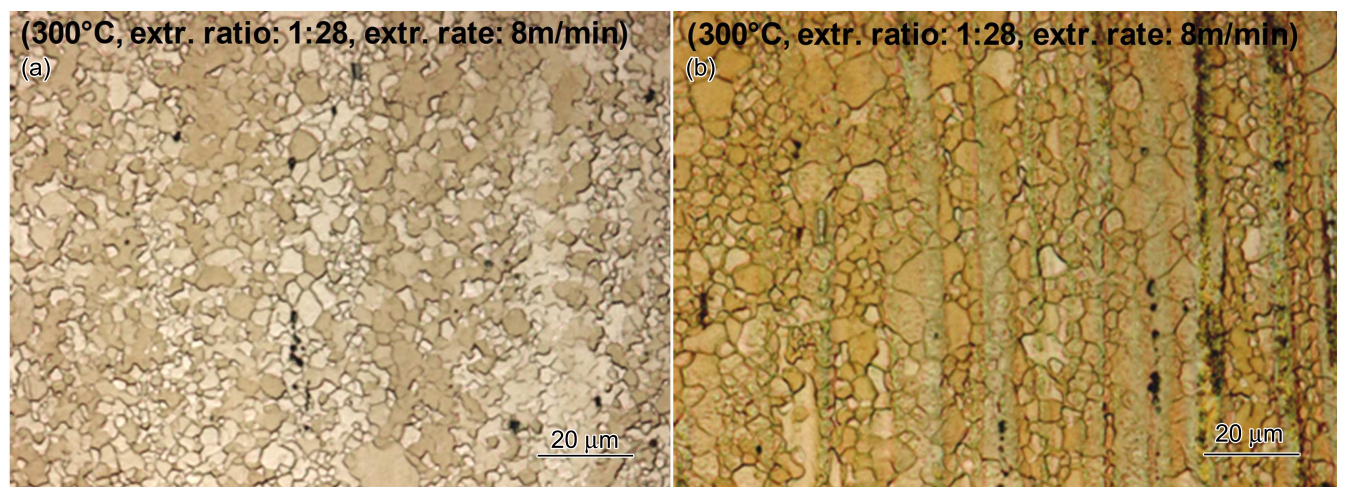

Fig. 10 Hydrostatically extruded magnesium alloys: (a) AZ31; (b) AZ61

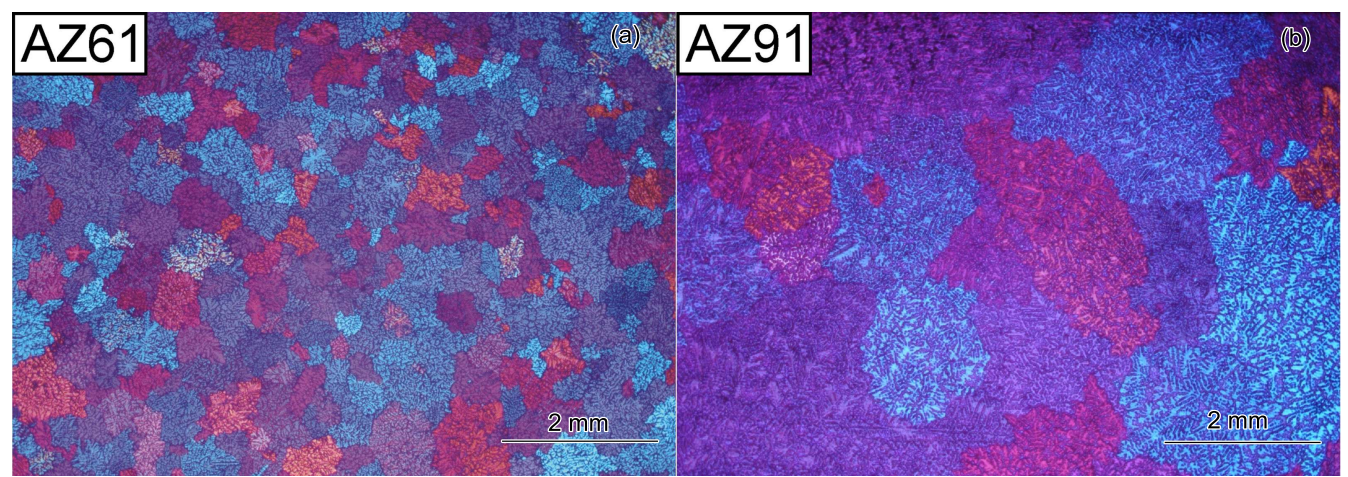

Fig. 11 Microstructure of as-cast magnesium alloys: (a) AZ61; (b) AZ91 
Table 5 Chemical composition (wt.\%) of AZ91 ${ }^{[10]}$

\begin{tabular}{cccccccccc}
\hline Alloy & Condition & $\mathrm{Al}$ & $\mathrm{Zn}$ & $\mathrm{Mn}$ & $\mathrm{Si}$ & $\mathrm{Fe}$ & $\mathrm{Cu}$ & $\mathrm{Ni}$ & $\mathrm{Be} / 10^{-6}$ \\
\hline AZ91 & Chill cast & 9.29 & 0.70 & 0.26 & 0.008 & 0.003 & 0.003 & 0.001 & 13 \\
\hline
\end{tabular}
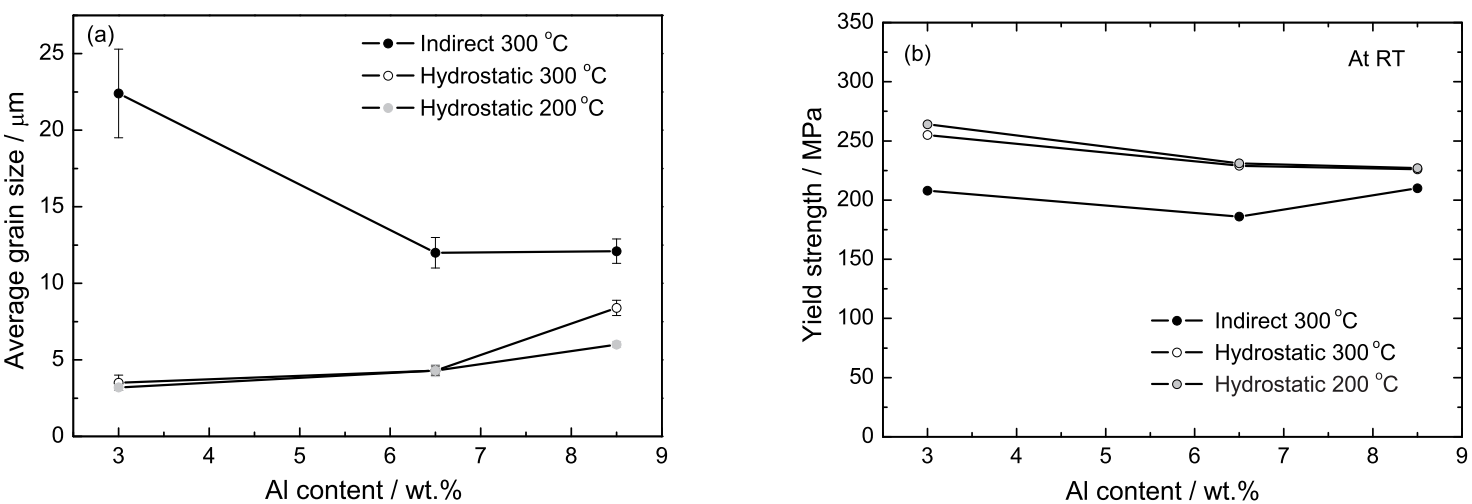

Fig. 12 Correlation between grain size (a) and yield strength (b) of extruded magnesium alloys, measured at room temperature $(\mathrm{RT})^{[11]}$.

than those of the hydrostatically extruded ones (Table 4).

Fig. 12 illustrates the influence of the grain size on the yield strength of different magnesium alloys. The additionally listed indirect extrusion (e.g. work of Swiostek et al. $\left.{ }^{[11]}\right)$ which represents a more common forming method leads to a higher grain size compared to the hydrostatically extruded samples and, consequently, to a lower yield strength. This behavior is explainable by the Hall-Petch relationship ${ }^{[12,13]}$ where the yield strength is inversely proportional to the square root of the grain size.

\section{Results and Discussion}

\subsection{Results of strain dependent damping measurements}

In Fig. 13 the damping in terms of the logarithmic decrement $\delta$ is plotted versus the maximum strain $\varepsilon_{\max }$ in logarithmic scale. All damping curves are offset corrected. The logarithmic decrement itself was determined from the curve fit of the decay curve (Fig. 2). This path was pursued to take account of noisy data which would lead to a broad scattering of $\delta$ arising from its calculation (due to the natural logarithm of the current amplitudes from the decay curve, Eq. (4)).

The hydrostatically extruded and fine-grained magnesium alloys AZ31 and AZ61 exhibit a damping which is nearly independent from the strain. This result could also be observed in former measurements of Göken et al. ${ }^{[6]}$ A strong strain dependence can be seen for the materials AZ61 and AZ91 in as received condition. Their microstructure is characterized by coarse grains, Fig. 11. It is obvious that the damping

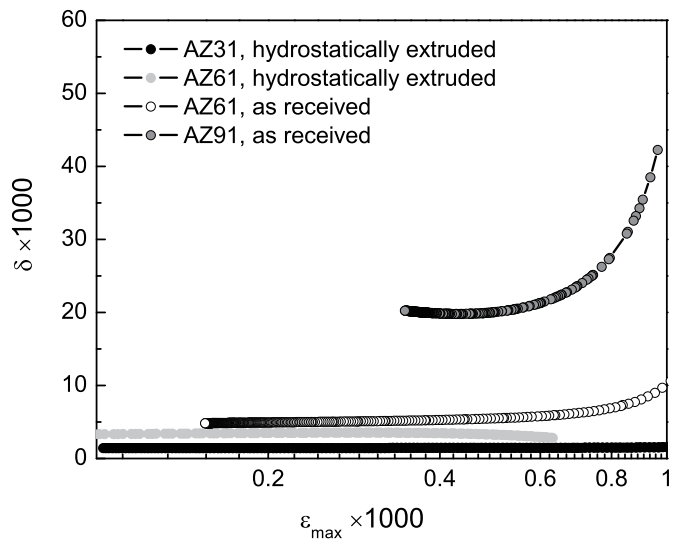

Fig. 13 Strain dependent damping curves of different magnesium alloys

level of the hydrostatically extruded AZ61 is higher than that of AZ31. According to Table 4 the grain size of AZ61 after hydrostatic extrusion is slightly larger and the yield strength lower than those for AZ31. The cast magnesium alloy AZ91 shows the strongest strain dependence and generally the highest materials damping.

\subsection{Dislocation model}

Damping exhibits a strong dependence on the amount of alloying elements and on the grain size which can be adjusted by the forming process. According to the dislocation model by Granato and Lücke (GL-model ${ }^{[14]}$ ) the materials damping is high when dislocations can move more freely. In higher alloyed alloys the alloying elements act as pinning points inhibiting the motion of dislocation segments. After hydrostatic forming which leads to a small grain size 


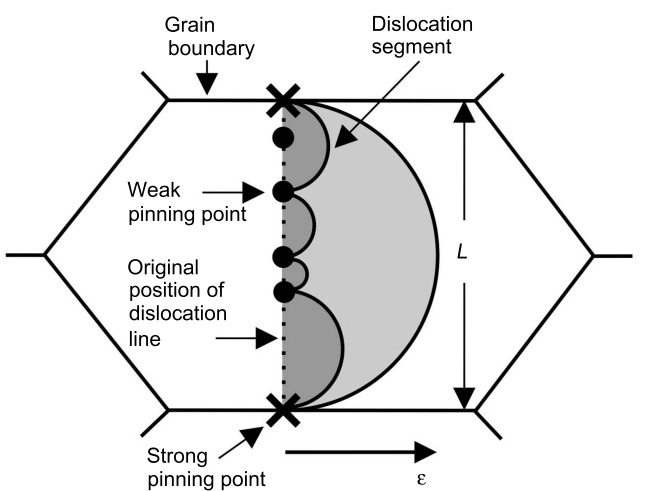

Fig. 14 Dependence of damping on grain size $L^{[15]}$

and higher strength (Fig. 12) the change of the damping behavior is describable by a simplified dislocation model as shown in Fig. 14 where the interaction between different obstacles and dislocations is illustrated. The alloying elements working as weak pinning points are distributed across the grain with grain size $L$. Strong pinners are located at the grain boundary.

When the external stress $\varepsilon$ increases dislocation segments bow out and break loose from the weak pinning points. This is reflected by a successive increase of the dependence of the materials damping on the strain amplitude. In case of a small grain the space for such a procedure is reduced compared to materials with a coarse grain size. Thereby, the necessary strain for the breaking away of the dislocation segments is higher for fine-grained microstructures ${ }^{[6]}$. This is the reason why an almost strain independent damping of hydrostatically extruded magnesium alloys AZ31 and AZ61 was measured.

\subsection{Further correlations}

As an approximated rule of thumb it can be said that the logarithmic decrement is reduced when the yield strength of a material rises and vice versa. Thus, the extruded AZ61 alloy should show a slightly higher damping as extruded AZ31 which was observed. According to Table 5 the cast magnesium alloy AZ91 consists of a higher amount of alloying elements than the cast magnesium alloy AZ61 (Table 2). This should cause a lower strain dependent damping of AZ91 compared to AZ61. But the grain size of AZ91 is nearly three times larger than the grain size of AZ61 (Fig. 11).

In Fig. 15 the data fluctuations taken from three strain dependent damping measurements of the hydrostatically extruded alloy AZ31 are shown. It is necessary to know if repeatable data can be received by this kind of damping measurement. A standard deviation of about $\pm 10 \%$ has to be considered.

\subsection{Colour-coded sound emission}

It was described that the position of the Microflown ${ }^{\mathrm{TM}}$ probe was near the clamped area where the lowest particle velocity is expected which means reduced sound fluctuations. The particle velocity can be visualized by colour coding and shows the most or less vibrating sections of the bending beam, respectively. The most vibrating section is colour-coded in red whereas the less vibrating area is colour-coded in blue (Fig. 16). According to Fig. 4 the free end of the specimen produces the highest elongation $z^{\prime}$ (= amplitude of vibration; Eq. (5)) leading to the maximum strain $\varepsilon_{\max }$ near the clamped side of the bending beam. In other words: When the particle velocity is high (area colour-coded in red) the amplitude of vibration (sound emission) of this special location of the sample is high. This experimental observation allows indirectly to find out where highly stressed areas can occur (in our case the clamped area). The colour coding method of the sound localization system is valuable because this procedure enables both a very economical and extremely thorough (in terms of technical mechanics) analysis of a complete structure system.

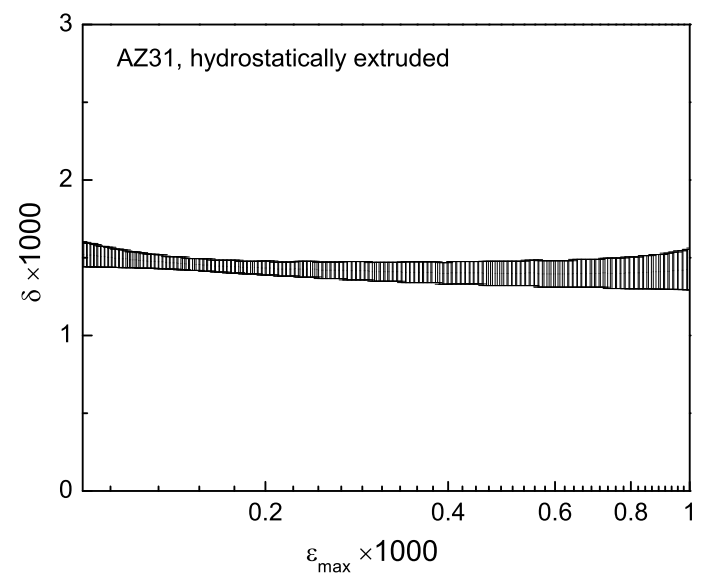

Fig. 15 Determination of reproducibility of the measured damping data

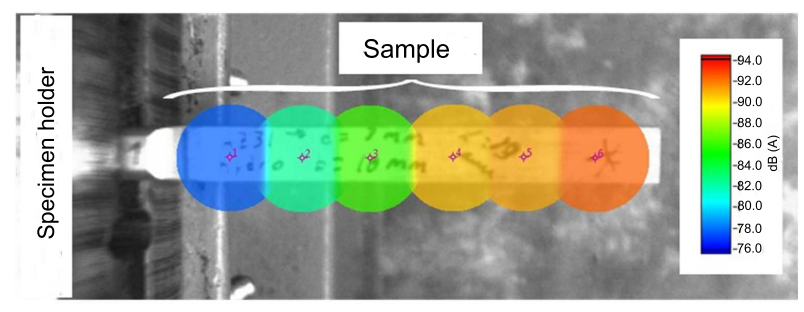

Fig. 16 Localisation of the sound emission by colour coding (red colour: high acoustic emission; blue colour: low acoustic emission; view from above) 

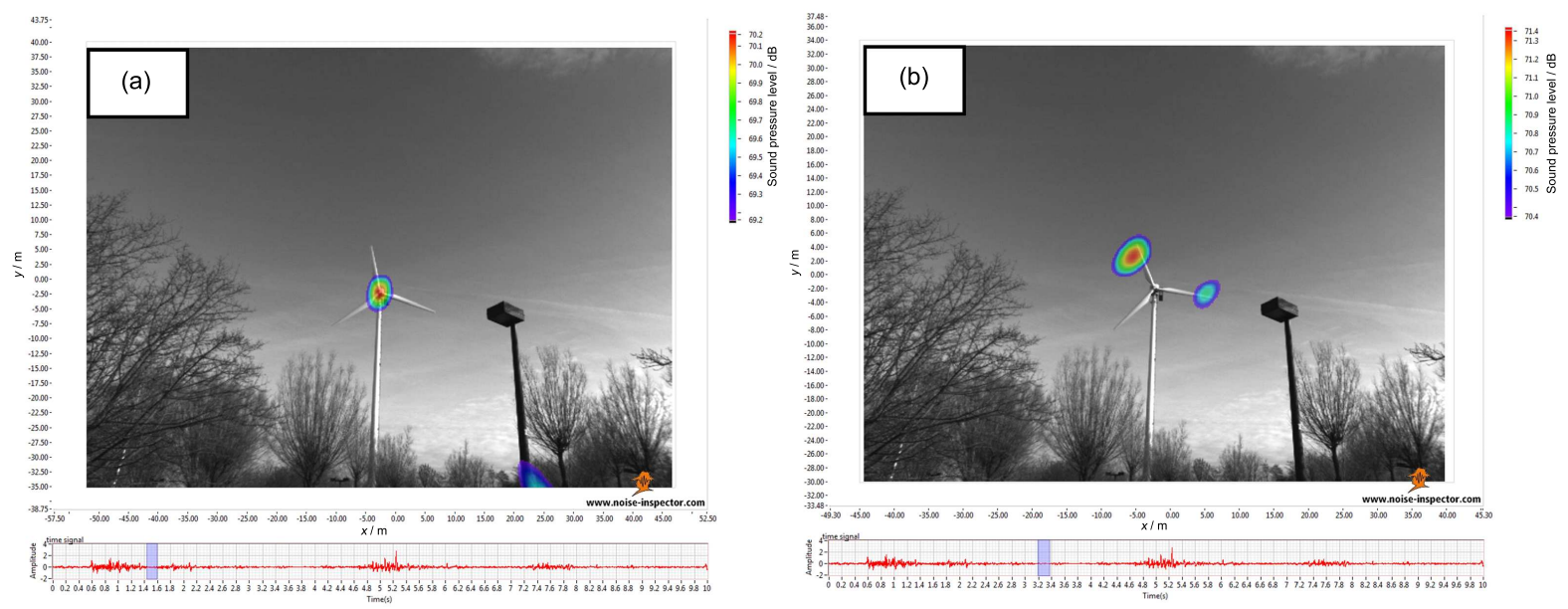

Fig. 17 Acoustic emission of a windmill visualized by colour coding: (a) from nacelle; (b) from rotor blade tips (red colour: high acoustic emission; blue colour: low acoustic emission)

\subsection{Outlook / Field of application}

Fig. 17 gives an outlook a contactless measuring acoustic system can be used for. The measurements were performed with an extended version of the sound source localization system using the sound pressure. It becomes clear that especially the nacelle (Fig. 17(a)) and the rotor blade tips (Fig. 17(b)) of the windmill cause a lot of noise which means on the one hand an unwanted energy loss and on the other hand higher mechanical stresses in sensitive structural elements which can lead to failure of these components. This failure is caused by microplasticity which is observable due to significant changes during measurements of the strain dependent damping. According to the received results of this work it can be pointed out that such a sound source localization system offers a huge potential because it is able to work as a quality tool (e.g. useful for maintenance activities) and for investigations concerning the correlation between microstructure and mechanical properties of components as shown in this paper.

\section{Conclusions}

A Microflown ${ }^{\mathrm{TM}}$ probe was used to determine the particle motion of the air caused by vibrating bending beams directly. These beams were made out of the magnesium alloys AZ31, AZ61 and AZ91 in different microstructural conditions. AZ31 and AZ61 were formed by hydrostatic extrusion which led to fine-grained structure (average grain size about $5 \mu \mathrm{m}$ ) and, hence, increased yield strength. Additionally, the coarse-grained magnesium alloys AZ61 and AZ91 in as received condition were used.

The materials damping in terms of the logarithmic decrement of these samples was determined by the decrease in particle velocity with time. It could be shown that the damping of the extruded alloys were low and nearly strain independent. The coarse grained magnesium alloys exhibited a higher damping which could be explained by increased movement of dislocations. When the strength rises by grain refinement a lower damping is observed. Besides this mechanism a higher alloying can contribute to a reduction of the damping because dislocations segments are pinned more effectively.

The use of a Microflown ${ }^{\mathrm{TM}}$ probe may help to investigate the vibration characteristics of a structural component. The reproducibility of the measured damping data existed (standard deviation of $\pm 10 \%$ ). This allows to control materials subjected to cyclic deformation and resonance loading with regard to their service life. Colour coding of the sound emission from oscillating components contributes to the assessment of dynamically stressed parts.

\section{Acknowledgements}

Prof. Dr. Jürgen Göken gratefully acknowledges the financial support of the German Research Foundation (DFG, www.dfg.de; DFG-reference number: INST 21572/1-1 LAGG) for the sound localisation system. Some measurements were done within the framework of the project "North Sea Supply Connect" (NSSC) being a part of the Interreg IVB North Sea Region Programme and cofinanced by the European Regional Development Fund. These measurements serve at the same time as preliminary tests for another project named "MariTIM" (Interreg IVA-Programme between Germany and the Netherlands being co-financed by the European Regional Development Fund (EFRE)). Prof. Dr. Jürgen Göken would like to take this opportunity to thank these funding programmes for their financial support.

\section{REFERENCES}

[1] Microflown ${ }^{\mathrm{TM}}$ Technologies, Charting Sound Fields (Manual, V1.0 - 03.2009).

[2] M.H. Sha, G.D. Shi, Y. Wang and J. Qiao, Trans. Nonferrous Met. Soc. China 20 (2010) 571. 
[3] T.V. Ivleva, J. Göken, I.S. Golovin, Z. Zuberova, M. Maikranz-Valentin and K. Steinhoff, Solid State Phen. 137 (2008) 181.

[4] I.S. Golovin, In: M.S. Blanter and Y.V. Piguzov (eds.), Metallurgizdat, Moscow, 1991, p. 133. (in Russian)

[5] I.S. Golovin and S.A. Golovin, Ferrous Metall. 5 (1989) 7. (in Russian)

[6] J. Göken, J. Swiostek, D. Letzig and K.U. Kainer, Mater. Sci. Forum 482 (2005) 387.

[7] M.F. Ashby, Materials Selection in Mechanical Design, Butterworth-Heinemann, Oxford, 1999, p. 48.

[8] J. Swiostek, J. Göken, D. Letzig and K.U. Kainer, Mater. Sci. Eng. A 424 (2006) 223.
[9] K. Müller, Grundlagen des Strangpressens, ExpertVerlag, Renningen, Germany, 2003. (in German)

[10] J. Göken, J. Swiostek, W. Riehemann, Z. Trojanová and P. Lukáč, Metall. Anal. 30 (2010) 978.

[11] J. Swiostek, J. Bohlen, D. Letzig and K.U. Kainer, Mater. Sci. Forum 488-489 (2005) 491.

[12] E.O. Hall, Proc. Phys. Soc. London B 64 (1951) 747.

[13] N.J. Petch, J. Iron Steel Inst. London 174 (1953) 25.

[14] A. Granato and K. Lücke, J. Appl. Phys. 27(6) (1956) 583

[15] G. Schoeck, E. Bisogni and S. Shyne, Acta Met. 12 (1964) 1466. 